\title{
Comparative Study of Pulp Vitality in Primary and Young Permanent Molars in Human Children with Pulse Oximeter and Electric Pulp Tester
}

\author{
${ }^{1}$ Prinka Shahi, ${ }^{2}$ PB Sood, ${ }^{3}$ Arun Sharma, ${ }^{4}$ Manish Madan, ${ }^{5}$ Nishat Shahi, ${ }^{6}$ Geetanjali Gandhi
}

\section{ABSTRACT}

Aim and objective: The purpose of this study was to compare the pulp testing methods (pulse oximetry and electric pulp test) in primary and young permanent teeth of children.

Materials and methods: The study included a total of 155 children aged 4 to 15 years. Twenty children formed control group I. Study group included all healthy, 85 primary 2 nd molars in group II and 85 permanent 1st molars in group III. Fifty children needing endodontics treatment formed test group IV. The readings were recorded as true positive (TP), false positive (FP), true negative (TN), false negative (FN). Based on this, the sensitivity, specificity, positive predictive value and negative predictive value were calculated for each method. The results were statistically analyzed using Chi-square test.

Results: On comparing pulse oximetry with electric pulp test 'p-value' was found to be 0.487 and 1.00 for groups 1 and 2 respectively and was statistically not significant. Whereas ' $p$-value' for groups 3 and 4 was $<0.0001$ and 0.003 respectively and was statistically highly significant.

Conclusion: The present study indicates that pulse oximetry can be used as a routine method for assessing the pulp vitality in primary, young permanent and mature permanent teeth.

Keywords: Electric pulp tester (EPT), Pulse oximeter, True positive (TP), True negative (TN), Vitality.

How to cite this article: Shahi P, Sood PB, Sharma A, Madan M, Shahi N, Gandhi G. Comparative Study of Pulp Vitality in Primary and Young Permanent Molars in Human Children with Pulse Oximeter and Electric Pulp Tester. Int J Clin Pediatr Dent 2015;8(2):94-98.

\footnotetext{
${ }^{1,6}$ Senior Lecturer, ${ }^{2-5}$ Professor

1,4,5 Department of Pedodontics, MM College of Dental Sciences and Research, Ambala, Haryana, India
}

${ }^{2}$ Department of Pedodontics, PDM Dental College Bahadurgarh Haryana, India

${ }^{3}$ Department of Pedodontics, Institute of Dental Studies and Technologies, Dental College, Ghaziabad, Uttar Pardesh, India

${ }^{6}$ Department of Orthodontics, MM College of Dental Sciences and Research, Ambala, Haryana, India

Corresponding Author: Prinka Shahi, Senior Lecturer Department of Pedodontics, MM College of Dental Sciences and Research, Ambala, Haryana, India, Phone: 01722609375 e-mail: p.shahi@ymail.com

\section{Source of support: Nil}

Conflict of interest: None

\section{INTRODUCTION}

The vitality of a pulp is function of vascular supply of the pulp within a tooth, and pulpal circulation is true determinant of pulp vitality. The assessment of pulpal status is a diagnostic challenge in clinical practice. An accurate diagnosis is important to achieve a good treatment outcome. The conventional pulp testing methods include thermal stimulation, electrical or direct dentin stimulation fall short of ideal pulp vitality testing as they indirectly monitor pulp vitality by measuring neural responses. ${ }^{1}$ A new approach to determine vital pulp tissue by optical technology includes dual wavelength spectrophotometry, Pulse oximetry, Laser doppler flowmetry, transmitted light-photoplehtysmography. These tests are noninvasive, objective, painless and are very sensitive to detect pulp blood components or blood flow. ${ }^{2}$

The present in vivo study was undertaken to evaluate and compare pulse oximeter and conventional pulp testing method (EPT) to assess pulp vitality in primary 2nd molar and young permanent 1st molar.

\section{MATERIALS AND METHODS}

The present in vivo study was conducted in the Department of Pedodontics and Preventive Dentistry, ITSCDSR, Muradnagar, Ghaziabad. Material used: Pulse oximeter with modified ear probe (Nellcor OxiMax) (Figs 1 and 2), Electric Pulp Tester (Gentle-Pulse, Parkell Electronics Division) (Fig. 3), Electrolyte media (toothpaste), cheek retractor, cotton rolls, disposable gloves.

\section{METHODS OF COLLECTION OF DATA}

The selection criteria in study group include children that are positively positive on Frankel rating scale between the age group between 6 and 8 years and teeth to be free of caries, restoration, trauma and developmental defect. Patients with any illness (epileptic, mentally challenged), periodontal or periapical pathology in the concerned tooth were excluded. 


\section{Source of Data}

One hundred and fifty-five cooperative children aged 4 to 15 years were divided into 4 groups. Group I (Control Group) 20 endodontically treated primary 2nd molars and permanent 1st molars. Group II (Study Group) included all healthy, eighty-five primary 2nd molars. Group III (Study Group) included all healthy, eighty-five young permanent 1st molars. Group IV (Test Group) included 50 teeth in need of endodontic treatment. After completing pulp vitality testing, the pulp chamber in test group teeth were opened for direct visual inspection.

\section{MATERIALS AND METHODS}

Prior to the study, Ethical clearance and informed consent was taken. Systemic oxygen saturation $\left(\mathrm{SaO}_{2}\right)$ of left index finger was measured first. Thereafter, ear probe of pulse oximetry was firmly placed on buccal surface on middle of the clinical crown for 30 seconds (Figs 4 and 5). Pulse oximetry value above $75 \%$ oxygen saturation was taken positive.

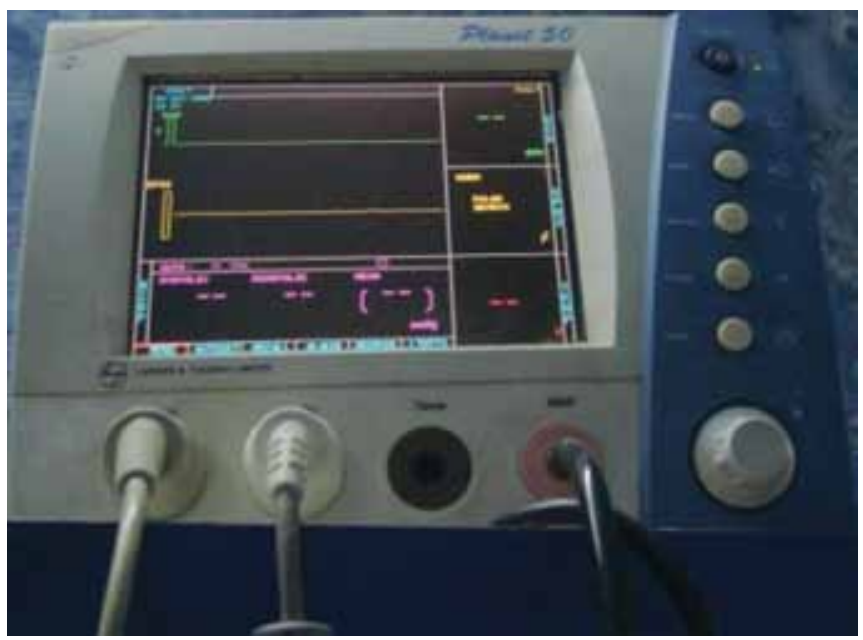

Fig. 1: Pulse oximeter

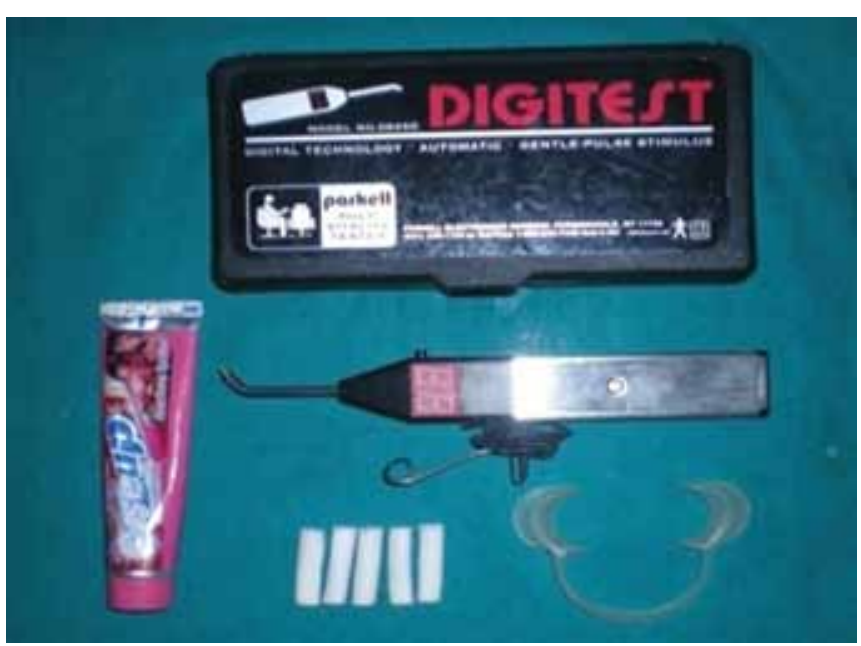

Fig. 3: Electric pulp tester
In electric pulp testing tooth was dried and isolated. Electrode was placed on middle of the clinical crown after toothpaste application ${ }^{3}$ (Fig. 6). The response at any level was scored as positive. No response to electrical test was scored as negative. Gloves were not worn during the test.

The readings were recorded as true positive (TP), false positive (FP), true negative (TN), false negative (FN). Based on this, the sensitivity, specificity, positive predictive value and negative predictive value were calculated for each method. Chi-square test was applied to determine statistical difference between pulse oximetry and electric pulp tester in all the four groups.

\section{RESULTS}

The pulse oximetry test identified all the endodontically treated nonvital teeth as nonvital, in group I. All the vital, primary 2nd molars and young permanent 1st molars were identified as vital, in groups II and III respectively. The pulse oximetry test gave 1 false negative reading, in group IV (Table 1).

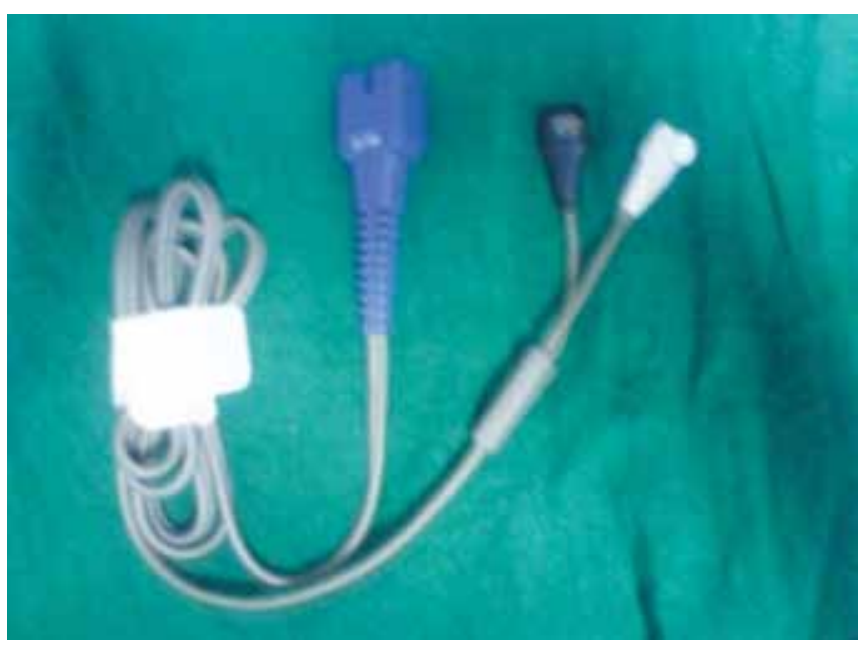

Fig. 2: Ear probe

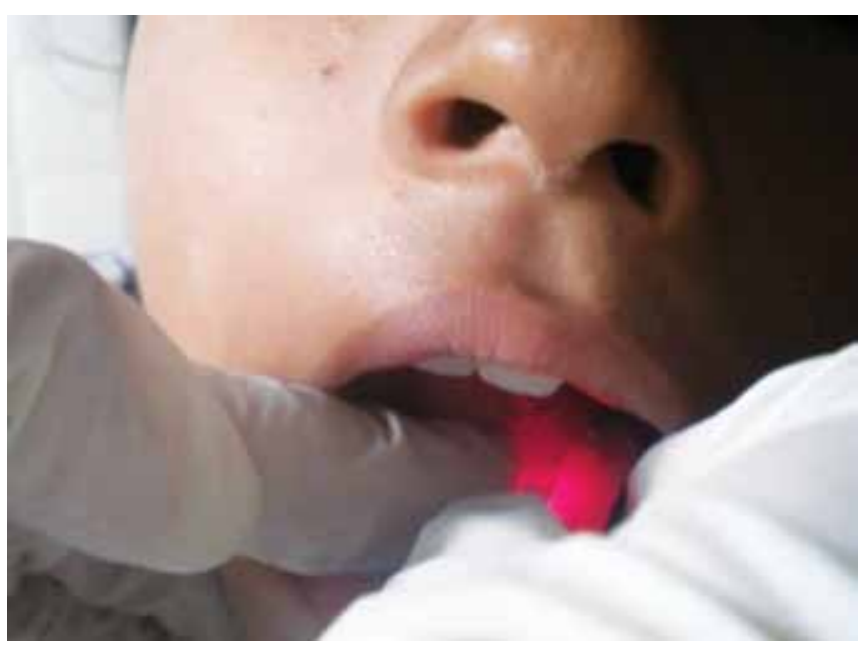

Fig. 4: Recording oxygen saturation 


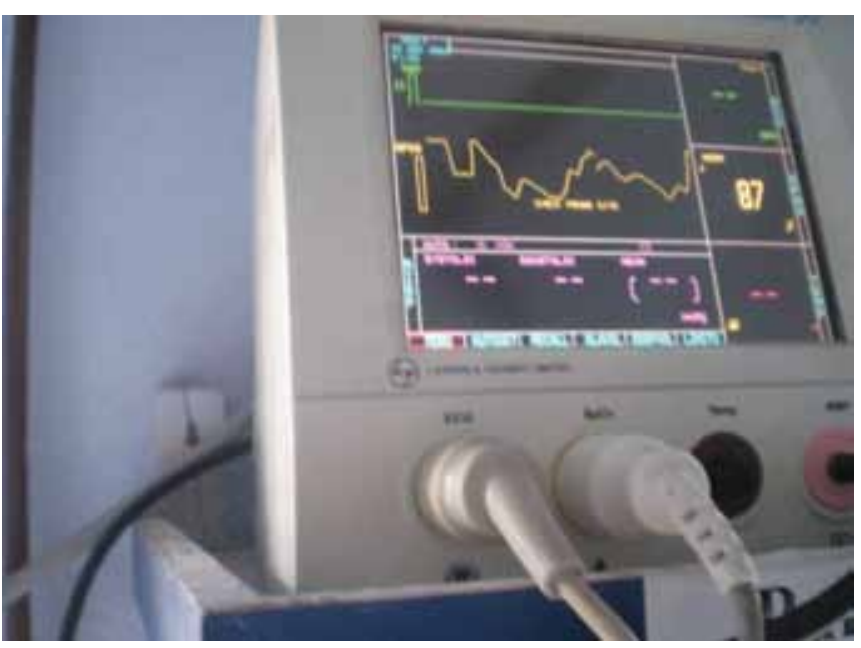

Fig. 5: Recording $\mathrm{SaO}_{2}$ value

Table 1: Distribution of response to pulse oximetry test in groups I to IV

\begin{tabular}{lllll}
\hline POxi & $T P$ & $F P$ & $F N$ & $T N$ \\
\hline Group I & 170 & 0 & 0 & 20 \\
Group II & 85 & 0 & 0 & 10 \\
Group III & 85 & 0 & 0 & 10 \\
Group IV & 39 & 0 & 1 & 10 \\
\hline
\end{tabular}

(TP: True positive; FP: False positive; FN: False negative; $\mathrm{TN}$ : True negative)

Table 3: Comparison between pulse oximetry and electric pulp test in groups I to IV

\begin{tabular}{lll}
\hline POxi vs EPT & $p$-value & $\begin{array}{l}\text { Level of } \\
\text { significance }\end{array}$ \\
\hline Group I & 0.487 & $\mathrm{NS}$ \\
Group II & 1.00 & $\mathrm{NS}$ \\
Group III & $<0.0001$ & $\mathrm{HS}$ \\
Group IV & 0.003 & $\mathrm{HS}$ \\
\hline
\end{tabular}

(NS: Not significant; HS: Highly significant)

The electric pulp test identified 18 of the 20 endodontically treated non-vital teeth as non-vital, whereas 2 endodontically treated teeth gave false positive responses, in group I. All the vital, primary 2nd molars were identified as vital, in group II. Of the 85 vital young permanent 1st molars the electric pulp test identified 85, whereas 17 vital teeth gave false negative responses, in group III. The electric pulp test gave 11 false responses, in group IV (Table 2).

On the basis of these findings, the sensitivity, specificity, positive predictive and negative predictive values, accuracy and level of significance ( $p$-value) were calculated for each method in Tables 3 and 4 respectively.

\section{DISCUSSION}

The assessment of pulpal status accurately is important to achievea good treatment outcome. All conventional vitality tests determined functioning of the nerves. The nerve response to stimulus may not be the true determinant of

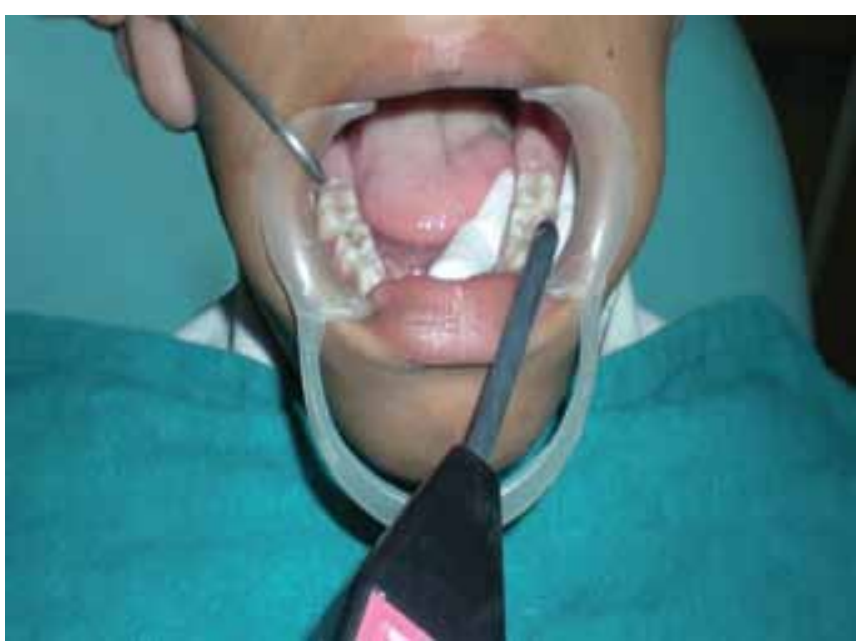

Fig. 6: Recording electric pulp tester response

Table 2: Distribution of response to electric pulp test in groups I to IV

\begin{tabular}{lllll}
\hline EPT & $T P$ & $F P$ & $F N$ & $T N$ \\
\hline Group I & 153 & 2 & 17 & 18 \\
Group II & 85 & 1 & 0 & 9 \\
Group III & 68 & 1 & 17 & 9 \\
Group IV & 35 & 5 & 6 & 4 \\
\hline
\end{tabular}

(TP: True positive; FP: False positive; FN: False negative; TN: True negative)

the pulp vitality ${ }^{2,4}$ as the life of the pulp tissue is dependent on the blood supply and not on nerve functioning, thus are not indicative of the vitality of a pulp. ${ }^{4}$ Among all the conventional vitality tests, EPT was found to be the relative effective method for checking the vitality of the pulp tissue of a tooth. ${ }^{5}$ Studies by Reynolds ${ }^{6}$ and Petersson ${ }^{7}$ also supported this fact.

The newer pulp testing devices, such as laser Doppler flowmetry, dual wavelength spectrophotometry, pulse oximetry and light photoplethysmography are noninvasive, objective and have shown more accurate results by detecting the blood supply of the pulp. The pulse oximeter is an affordable, reliable and easily available equipment for an average dental office. ${ }^{2}$ Hence, these two methods were selected for the study.

All the 20 endodontically treated primary 2 nd molars and permanent 1st molars recorded $\mathrm{SaO}_{2}$ values of $0 \%$ with pulse oximetry. Studies by Goho $\mathrm{C}^{8}$ and Gopikrishna ${ }^{9}$ also recorded $0 \% \mathrm{SaO}_{2}$ values on known endodontically treated primary teeth.

The present study showed that all the healthy 85 primary 2nd molars (Group II) and 85 permanent 1st molars (Group III) provided consistent oxygen saturation readings with pulse oximeter. Studies by Gopikrishna, ${ }^{9}$ Goho $C_{,}^{8}$ Caliil $^{10}$ and Gopikrishna ${ }^{11}$ have also shown consistent oxygen saturation reading in all vital teeth with pulse oximeter. This demonstrates the ability of the pulse oximeter to differentiate between vital and non-vital teeth. 
Table 4: Comparison of sensitivity, specificity, positive predictive value, negative predictive value and accuracy in groups I to IV

\begin{tabular}{|c|c|c|c|c|c|c|c|c|c|c|}
\hline \multirow[b]{2}{*}{ Groups } & \multicolumn{4}{|c|}{ POxi } & \multicolumn{6}{|c|}{$E P T$} \\
\hline & Sensitivity & Specificity & $P P V$ & $N P V$ & Accuracy & Sensitivity & Specificity & $P P V$ & $N P V$ & Accuracy \\
\hline I & 1.00 & 1.00 & 1.00 & 1.00 & 1.00 & 0.90 & 0.90 & 0.98 & 0.51 & 0.90 \\
\hline II & 1.00 & 1.00 & 1.00 & 1.00 & 1.00 & 1.00 & 0.90 & 0.98 & 1.00 & 1.00 \\
\hline III & 1.00 & 1.00 & 1.00 & 1.00 & 1.00 & 0.80 & 0.90 & 0.99 & 0.35 & 0.80 \\
\hline IV & 0.98 & 1.00 & 1.00 & 0.91 & 1.00 & 0.85 & 0.44 & 0.87 & 0.40 & 0.78 \\
\hline
\end{tabular}

(PPV: Positive Predictive Value; NPV: Negative Predictive Value)

Group IV has shown one $\mathrm{FN}$ reading with $\mathrm{SaO}_{2}$ value of $0 \%$, whereas surgically exposed pulp showed sign of normal bleeding. In a study by Gopikrishna, out of 38 vital teeth in need of endodontic treatment, the pulse oximetry test identified 36 , whereas two of the vital pulps did not show $\mathrm{SaO}_{2}$ to pulse oximetry. ${ }^{1}$ Motion artefact or non-parallelism of probes have been suggested as possible reasons for false reading (Kahan). ${ }^{12}$

In electric pulp testing group 1 showed $10 \%$ of false response. Whereas, group II gave $100 \%$ positive responses. In young permanent 1st molars EPT showed $20 \%$ false responses. Reason for false negative responses in young permanent 1st molars could be-the increased electrometric threshold value in teeth with incomplete root formation, and neural development is incomplete in immature teeth. ${ }^{13}$

Total of 11 out of 50 affected due to disease/trauma showed false responses with EPT. EPT has shown $22 \%$ failure. Gopikrishna has found a failure of $18.7 \%$ and Petersson has found $18.6 \%$ on diseased teeth with EPT. False responses with electric pulp testing could be-traumatized teeth, teeth with incomplete root development, teeth undergone orthodontic tooth movement, pulp canal calcifications. Or the peridental membrane response because of conduction along the moist surface of the tooth, multirooted teeth, patient's anxiety. ${ }^{14,15}$

In group I (endodontically treated teeth), the sensitivity of pulse oximetry and electric pulp test was 1.00 and 0.90 respectively. The sensitivity of pulse oximetry and electric pulp test were 1.00 in group II (mature teeth). In group III (immature teeth) sensitivity were 1.00 and 0.90 respectively with pulse oximetry and electric pulp test and 0.98 and 0.85 respectively with pulse oximetry and electric pulp test in group IV (diseased teeth). The sensitivity of the pulse oximeter in a study of Gopikrishna ${ }^{1}$ was found to be 1.00 , as compared to 0.71 with the electrical test on diseased teeth.

In the present study, the specificity of the pulse oximetry and electric pulp test was 1.00 and 0.90 for groups I, II and III. The specificity of the pulse oximetry and electric pulp test in group IV were 1.00 and 0.44 respectively. The specificity of the pulse oximeter in a study of Gopikrishna ${ }^{15}$ was found to be 0.95 , as compared to 0.92 with the electrical test on diseased teeth.

Goho $\mathrm{C}^{8}$ evaluated pulp vitality in primary and immature permanent teeth using pulse oximeter and found both sensitivity and specificity to be 1.00. Shender $^{16}$ has concluded the same results with pulse oximeter from his review.

Consistent pulse oximeter readings in this study confirm that pulp circulation and blood oxygen saturation can be detected by pulse oximeter and may be used as a standard and as an indicator of pulp vitality irrespective of the health of tooth, the status of development of tooth, type of dentition and status of disease. Electric pulp testing has a reasonable reliability in primary dentition to evaluate its status of health but it has not been found effective in conditions where the pulp is affected by either a disease process or trauma. Thus, pulse oximeter can be used as an effective diagnostic aid in clinical practice.

\section{CONCLUSION}

This study shows that pulse oximeter is an objective, very sensitive and noninvasive method that can be used as a routine method for assessing the pulp vitality in primary, young permanent and mature permanent teeth. Furthermore, an accurate and immediate diagnosis of pulpal status in traumatized teeth is possible with pulse oximetry. There is a need to evolve the data to suggest saturated oxygen value of the pulpal tissue in terms of percentage as an indicator of the health or disease of the pulp.

\section{REFERENCES}

1. Gopikrishna V, Tinagupta K, Kandaswamy D. Evaluation of efficacy of a new custom-made pulse oximeter dental probe in comparison with the electrical and thermal tests for assessing pulp vitality. J Endod 2007;33(4):411-414.

2. Samraj RV, Indra R, Srinivasan MR, Kumar A. Recent advances in pulp vitality testing. Endodontology 2003;15(1): 14-19.

3. Kolbinson DA, Teplitsky PE. Electric pulp testing with examination gloves. Oral Surg Oral Med Oral Pathol 1988; 65(1):122-126.

4. Bhaskar SN, Rappaport HW. Dental vitality tests and pulp status. J Am Dent Assoc 1973;86(2):409-411. 
5. Degering CI. Physiologic evaluation of dental-pulp testing methods. J Dent Res 1962;41(3):695-700.

6. Reynolds RL. The determination of pulp vitality by means of thermal and electrical stimuli. Oral Surg Oral Med Oral Pathol 1966;22(2):231-240.

7. Petersson K, Soderstrom C, Kiani-Anaraki M, Levy G. Evaluation of the ability of thermal and electrical tests to register pulp vitality. Endod Dent Traum 1999;15(3):127-131.

8. Goho C. Pulse oximetry evaluation of vitality in primary and immature permanent teeth. Pediatr Dent 1999;21(2): 125-127.

9. Gopikrishna V, Kandaswamy D, Tinagupta. Assessment of the efficacy of an indigenously developed pulse oximeter dental sensor holder for pulp vitality testing. Ind J Dent Res 2006;17(3):111-113.

10. Calil E, Caldeira CL, Gavini G, Lemos EM. Determination of pulp vitality in vivo with pulse oximetry. Int Endod J 2008; 41(9):741-746.
11. Gopikrishna V, Tinagupta, Kandaswamy D. Comparison of electrical, thermal and pulse oximetry methods for assessing pulp vitality in recently traumatized teeth. J Endod 2007; 33(5):531-534.

12. Kahan RS, Gulabivala K, Snook M, Setechell DJ. Evaluation of a pulse oximeter and customized probe for pulp vitality testing. J Endod 1996;22(3):105-109.

13. Johnsen DC, Harshbarger J, Rymer HD. Quantitative assessment of neural development in human premolars. Anat Rec 1983;205(4):421-429.

14. Chen E, Abbott PV. Dental pulp testing: a review. Int J Dent 2009;1-12.

15. Gopikrishna V, Pradeep G, Venkateshbabu N. Assessment of pulp vitality: a review. Int J Paedtr Dent 2009;19(1):3-15.

16. Shender O, Shora S, Siddiqui S, Tchaouchev N, Termei R, Terzioglu U, Toor N, Vishwanath S. How helpful are diagnostic tests for pulp conditions? 2007;1-15. 